\title{
Dynamic rupture propagation during the 1891 Nobi, central Japan, earthquake: A possible extension to the branched faults
}

\section{$\operatorname{AUTHOR}(\mathrm{S})$ :}

Fukuyama, Eiichi; Mikumo, Takeshi

\section{CITATION:}

Fukuyama, Eiichi ... [et al]. Dynamic rupture propagation during the 1891 Nobi, central Japan, earthquake: A possible extension to the branched faults. Bulletin of the

Seismological Society of America 2006, 96(4): 1257-1266

\section{ISSUE DATE:}

2006-08

URL:

http://hdl.handle.net/2433/193417

RIGHT:

(C) 2006 Bulletin of the Seismological Society of America 


\title{
Dynamic Rupture Propagation during the 1891 Nobi, Central Japan, Earthquake: A Possible Extension to the Branched Faults
}

\author{
by Eiichi Fukuyama and Takeshi Mikumo
}

\begin{abstract}
The dynamic rupture process of the 1891 Nobi, Japan, earthquake was closely reinvestigated by using a boundary integral equation method based on currently available observations. We discussed mainly a possibility of the rupture propagation on branched faults, including a buried fault called the Gifu-Ichinomiya line. Several numerical simulations were made incorporating the information on the fault geometry based on the active fault traces on the ground surface and the maximum principal strain direction observed by the triangular surveys for the past 100 years. The results suggest that the rupture should propagate along the buried fault during the Nobi earthquake if a weak geological discontinuity exists along the GifuIchinomiya line and is connected to the Neodani fault, which is one of the major surface faults appearing during the Nobi earthquake.
\end{abstract}

\section{Introduction}

It has often been observed that earthquake rupture propagates along pre-existing faults with complex geometry in the continental crust. These fault complexities, sometimes referred to as nonplanar faults, include fault bending, jogs, step-overs, offsets, and fault branches. Actually, on the San Andreas fault system, several earthquakes such as the 1966 Parkfield, 1966 Borrego Mountain, 1979 Coyote Lake (Sibson, 1986), 1979 Imperial Valley (Archuleta, 1984), 1992 Landers (Aochi and Fukuyama, 2002), and 1999 Hector Mine (Oglesby et al., 2003) earthquakes show these complex patterns of rupture propagation. In some other regions, similar types of rupture propagation have also been observed; for example, the 1891 Nobi, Japan (Mikumo and Ando, 1976), 1920 Haiyuan, China (Deng et al., 1986), 1957 Mongolian, 1990 Luzon, Philippine (Nakata et al., 1990; Yoshida and Abe, 1992), 1999 Izumit, Turkey (Harris et al., 2002), and 2002 Denali, Alaska (e.g., Haeussler et al., 2004; Oglesby et al., 2004) earthquakes.

To understand the physics of rupture propagation on these complex fault systems, several theoretical and numerical studies have so far been made with 2D and 3D dynamic models; for parallel faults with offsets (Harris et al., 1991; Harris and Day, 1993), for bending faults (Tada and Yamashita, 1997; Bouchon and Streiff, 1997; Aochi et al., 2000; Cruz-Atienza and Vireux, 2004), for orthogonal faults (Kase and Kuge, 1998, 2001), for echelon faults (Harris and Day, 1999), and for branched faults (Kame and Yamashita, 1999; Aochi et al., 2000; Aochi and Fukuyama, 2002; Poliakov et al., 2002; Kame et al., 2003). In particular, Aochi et al. (2000) dealt with spontaneous dynamic rupture propagation on a branched-fault system in a 3D homogeneous medium under heterogeneous stress distribution, which clar- ified the selectivity conditions of rupture propagated on the main and branched faults.

As described in the next section, the 1891 Nobi earthquake in central Honshu, Japan, appears to have ruptured branched faults, although one of them did not break the ground surface, and hence there has been much debate about its existence up to this time. In the present study, we investigate the possibility of this rupture propagation on the branched-fault system, by applying the conditions given by Aochi et al. (2000) and the numerical method by Fukuyama et al. (2002), Fukuyama (2003), and Tada (2006), with reference to various observations described later.

\section{The 1891 Nobi Earthquake $(M \sim 8)$ in Central Honshu, Japan}

The Nobi earthquake $(M \sim 8)$ of 28 October 1891 was the greatest inland earthquake ever experienced in the Japanese Islands that was accompanied by long surface-fault breaks extending over $80 \mathrm{~km}$ with unusually large horizontal displacements up to $8 \mathrm{~m}$. The surface-fault breaks had been traced initially by Koto (1893) and Omori (1910), and more recently by Matsuda (1974) from detailed field surveys. Figure 1 shows these fault traces (Matsuda, 1974), and Table 1 summarizes the main-fault segments with their length, strike direction, and the range of the horizontal offsets, based on Matsuda (1974). The surface faults consist of three segments: Nukumi fault ( $\left.\mathrm{aa}^{\prime}\right)$, Neodani fault $\left(\mathrm{a}^{\prime} \mathrm{c}\right)$, and Umehara fault (cd).

In addition, the possible existence of a buried fault is suggested, which branched off at near point $\mathrm{c}$ in Figure 1, 


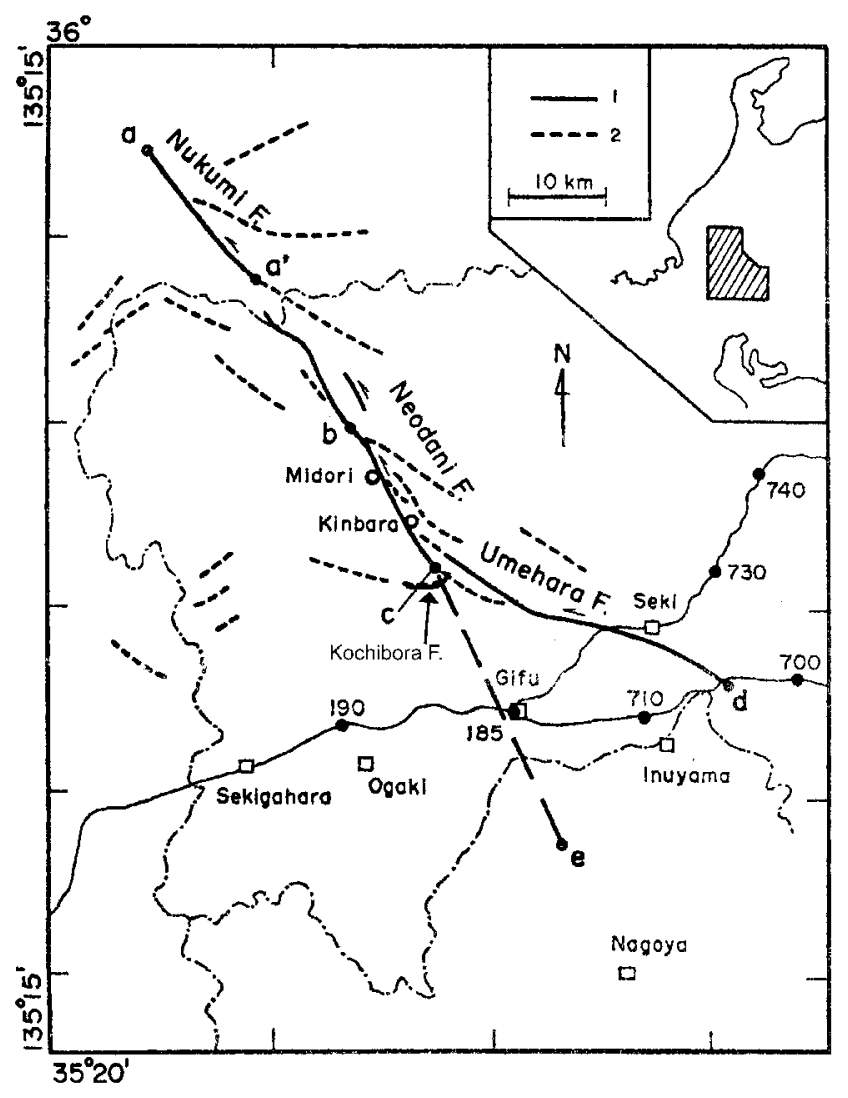

Figure 1. Fault traces ruptured during the 1891 Nobi earthquake (Matsuda, 1974) (1; solid lines), as well as the active faults around this region $(2$; dotted lines), are shown. The buried fault proposed by Mikumo and Ando (1976) (Gifu-Ichinomiya line) is also shown with a straight broken line. The Kochibora fault is also shown as a solid line.

extending southward through Gifu-Ichinomiya possibly down to point e near Nagoya. Here we call it the GifuIchinomiya line. It has been suggested based on various observations, including large accelerations along this line (Omori, 1894), seismic-intensity distribution inferred from the rates of collapsed houses, a gap between tectonic uplift and subsidence across this line, surficial ground fissures (Muramatu, 1963), shallow underground structure inferred from deep-well data (Sugisaki and Shibata, 1961), a relation between the collapsed rates and the thickness of alluvial layers (Yokoo and Horiuchi, 1969), and also some discontinuity of gravity anomalies across this line (Iida and Aoki, 1959).

Mikumo and Ando (1976) calculated vertical and horizontal deformations from 3D static dislocation models with the fault displacements on the major fault segments (Matsuda, 1974) and compared them with the coseismic uplift and subsidence along two leveling routes (Geographical Survey Institute, 1973) and also with the horizontal deformation from triangular surveys (Sato, 1974). They interpreted that the observed coseismic deformation can better be explained if the buried fault actually exists. Pollitz and Sacks (1994) assumed the existence of the buried vertical fault with two thrust faults dipping northwestward, to explain vertical deformation along another leveling route extending toward $\mathrm{Na}-$ goya. Nakano et al. (2003) also postulated a buried thrustfault model dipping eastward along the Gifu-Ichinomiya line to account for the vertical deformation and aftershock activity in the area between the Umehara fault and the GifuIchinomiya line.

In contrast to these interpretations, the Earthquake Research Committee (Okada, 2002) ruled out the possibility of the existence of any active faults along and around the GifuIchinomiya line, based on stratigraphic examinations of shallow-well records together with some results from seismic-reflection surveys (Aichi Prefecture, 1998, 2000). However, more detailed stratigraphic surveys of pumice and gravel beds from many more borehole records, which were made recently over an extensive area, revealed shallow underground vertical offsets at a depth of about 25-30 m along a line located $1.5 \mathrm{~km}$ east of the previously presumed location (Sugisaki and Shibata, 2003). They regarded these offsets as a strong indication of the buried fault that displaced during the 1891 earthquake and previous large events during the Quaternary age.

\section{Static Stress Field around the Fault}

First, we investigate the stress field from various existing data. Although static stress drop has been roughly estimated for two fault segments (Mikumo and Ando, 1976), we recalculated here the possible range of static stress drop on five fault segments; the Nukumi fault (aa'), the northern part of the Neodani fault $\left(a^{\prime} b\right)$, its southern part (bc), the Umehara fault (cd), and the Gifu-Ichinomiya line (ce) (Fig. 1, Table 1). To estimate the possible horizontal displacement on the buried fault (ce), assuming that it has actually displaced during the 1891 earthquake, we use the triple-junction kinematics proposed by Andrews (1989). The rigid-body displacements at this junction require that the ratio of slip to the sine of the opposite angle be the same for all three intersecting segments, that is, $D_{\mathrm{bc}} / \sin \alpha=D_{\mathrm{cd}} / \sin$ $\beta=D_{\text {ce }} / \sin \gamma$, where angles $\alpha, \beta$, and $\gamma$ are each less than $180^{\circ}$. Two angles, $\alpha$, the angle between the two segments $c d$ and ce, and $\gamma$, the angle between the two segments bc and $\mathrm{cd}$, are taken from the strike directions of these segments indicated in Table 1, as $\alpha=44^{\circ}$ and $\gamma=140^{\circ}$. The angle $\alpha$ is wide enough for the rupture to propagate on two branched faults (Aochi et al., 2000). While $D_{\mathrm{bc}}$ ranges between 4.0 and $6.5 \mathrm{~m}$, the slip near the southern end (point c) drops down to about $2 \mathrm{~m}$ (Matsuda, 1974). Using these values, $D_{\text {ce }}$ on the possible buried fault would be about 1.5$1.8 \mathrm{~m}$. This is comparable to the vertical offset in the first shallow layer along this line (Sugisaki and Shibata, 2003).

For calculating the static stress drop, we refer to Chinnery (1969), in which the stress drop on a vertical fault intersecting the surface can be evaluated at the center of the fault, from the fault length and width, the horizontal dis- 
Table 1

Fault Parameters for the 1891 Nobi Earthquake

\begin{tabular}{cccccc}
\hline Segment & $\begin{array}{c}\text { Strike } \\
\left(\mathrm{N}^{\circ} \mathrm{W}\right)\end{array}$ & $\begin{array}{c}\text { Length } \\
L(\mathrm{~km})\end{array}$ & $\begin{array}{c}\text { Depth* } \\
W(\mathrm{~km})\end{array}$ & $\begin{array}{c}\text { Slip } \\
D(\mathrm{~m})\end{array}$ & $\begin{array}{c}\text { Stress Drop } \\
(\mathrm{MPa})\end{array}$ \\
\hline $\mathrm{aa}^{\prime}$ & 40 & 20 & 15 & $1.0-2.0$ & $1.7-3.3$ \\
$\mathrm{a}^{\prime} \mathrm{b}$ & 30 & 18 & 15 & $2.0-3.0$ & $3.6-5.5$ \\
$\mathrm{bc}$ & 28 & 17 & 15 & $4.0-7.0$ & $7.7-12.9$ \\
$\mathrm{~cd}$ & 68 & 32 & 15 & $1.5-3.0$ & $1.8-3.6$ \\
$\mathrm{ce}^{*}$ & $24^{*}$ & $35^{*}$ & 15 & $1.3-1.8^{\dagger}$ & $1.3-2.0$ \\
\hline
\end{tabular}

*Assumed.

${ }^{\dagger}$ Estimated from the triple-junction kinematics (Andrews, 1989).

placement, and rigidity. In actual earthquake faults, the displacement may not be constant over the fault plane but might be amplified near the ground surface because of the effects of low-rigidity surface layers when the fault breaks the surface (Mikumo et al., 1987). Because it is difficult to estimate its depth profile at this moment without any more data, however, we simply assume the horizontal surface displacements observed by Matsuda (1974) over the entire fault depth. The fault depth is not well known, but it is assumed to be $15 \mathrm{~km}$ for all segments because the lowest limit of aftershock activity is at about this depth (Ooida et al., 1971). The stress drop thus estimated on each fault segment is shown in Table 1, where the average rigidity is taken to be $3.3 \times 10^{10}$ $\mathrm{N} / \mathrm{m}^{2}$.

For the computation of spontaneous rupture propagation, it is necessary to incorporate the information on the total stress field over the fault zone prior to the earthquake. For this purpose, we refer to the maximum strain rates measured by the Geographical Survey Institute (1994) for the 100 years from 1893 to 1994 . Figure 2 shows that the direction of the strain rates ranges between $\mathrm{N} 90^{\circ} \mathrm{E}$ and $\mathrm{N} 110^{\circ} \mathrm{E}$ in this region. This is also consistent with the direction of compressive tectonic stress over this region derived from recent Global Positioning System (GPS) observations (e.g. Geographical Survey Institute, 1999).

On the other hand, hydraulic fracturing stress measurements have been conducted recently down to a depth of $1300 \mathrm{~m}$ near the Midori fault, which is a minor branch of the main Neodani fault, as part of Active Fault Drilling project by the National Research Institute for Earth Sciences and Disaster Prevention (Ikeda et al., 1996). The results indicate that the maximum compressive stress lies in the northwest-southeast direction, which deviates somewhat from the previous estimates. Note, however, that the Midori fault is located close to a small triangular area that was uplifted during the earthquake with a large vertical offset $(\sim 6 \mathrm{~m})$ (Matsuda, 1974). Because we believe that this is due to unusual local fault geometry in this region, our fault model does not take into account such a local small-scale fault structure.

We will simulate spontaneous dynamic rupture propagation on the possible branched-fault system, taking into consideration the static stress field in this region, to investigate whether the rupture actually propagated along the buried fault (ce) during the 1891 earthquake.

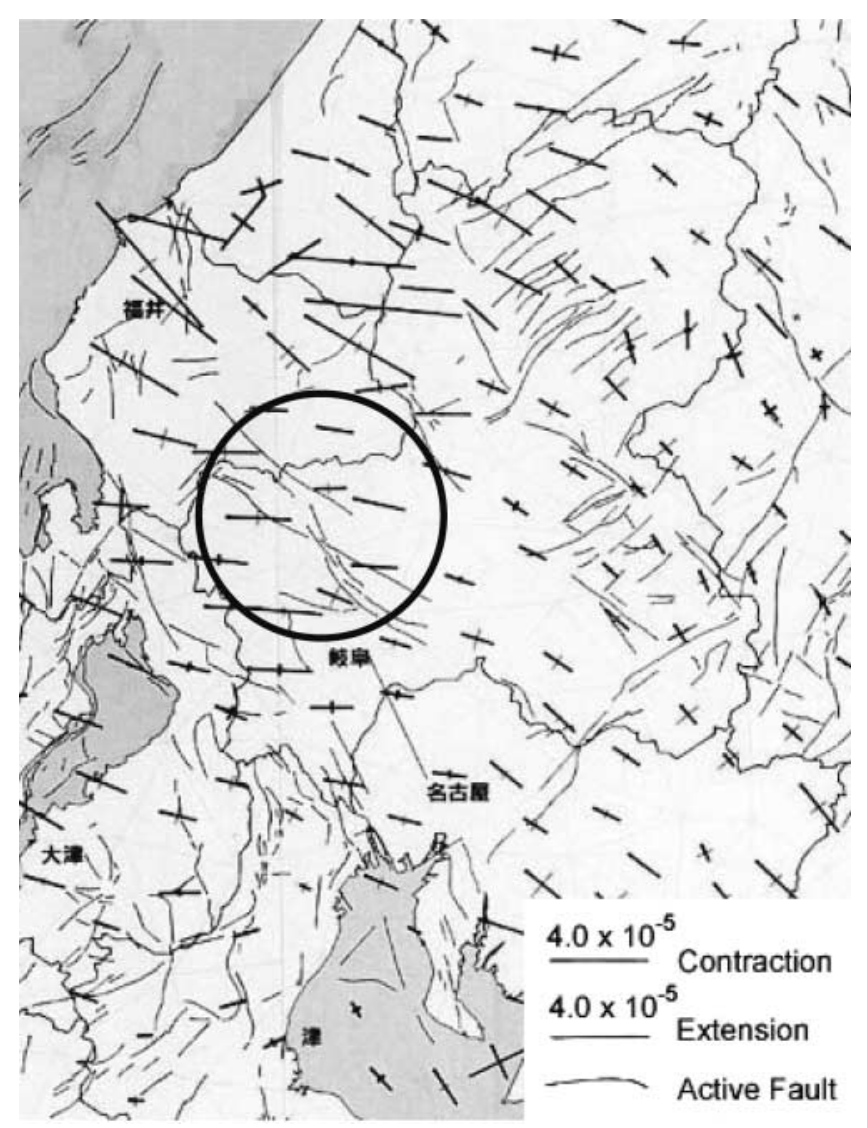

Figure 2. Distribution of horizontal principal strains in central Honshu, Japan (Geographical Survey Institute, 1994). The solid circle represents the source region of the 1891 Nobi earthquake.

\section{Dynamic Rupture Propagation}

The previous study (Mikumo and Ando, 1976) provided the general features of the faulting process, combining various data, including the fault displacements estimated by Matsuda (1974), predominant directions of ground motion at various sites, and old seismograph records at two nearby then-existing stations, with the application of a 3D kinematic dislocation model.

To simulate dynamic rupture propagation, we need the fault geometry, the magnitude and direction of stress applied to the fault, and the fault constitutive relation on the fault. In this simulation, the fault geometry is based on the model adopted by Mikumo and Ando (1976) as shown in Figure 3. Here we assumed vertical faults (i.e., dip angles of all fault segments are assumed to be $90^{\circ}$ ) extending down to a depth of $15 \mathrm{~km}$. On each fault, slip is assumed to occur only in the horizontal direction (i.e., pure strike-slip). On the other hand, the old seismograph records at the two stations that existed at that time went off scale, probably because of the arrival of large-amplitude $S$ waves. These times after triggering of the records were about $8 \mathrm{sec}$ at Gifu and $13.5 \mathrm{sec}$ at Nagoya (Mikumo and Ando, 1976). If these times can actually be 
regarded as $S$-P times, the distance to the rupture initiation point would be about $69 \mathrm{~km}$ and $109 \mathrm{~km}$ from the two stations, respectively, referring to the upper crustal $P$ - and $S$ wave velocities as $6.0 \mathrm{~km} / \mathrm{sec}$ and $3.5 \mathrm{~km} / \mathrm{sec}$ (Aoki et al., 1972). Apparently, these two epicentral distances converge somewhere near the northwestern edge (point a) of the $\mathrm{Nu}$ kumi fault. Accordingly, we assumed that the rupture initiated near this point at a depth of $10 \mathrm{~km}$. Here we consider two possible fault models: one with a branch from the main fault to the buried fault and the other without a branch to the buried fault. This aims at examining the possible existence of a fault branch to the buried fault from the viewpoint of the numerical simulations.

For the stress field, we assumed the maximum $\left(\sigma_{1}\right)$, intermediate $\left(\sigma_{2}\right)$, and minimum $\left(\sigma_{3}\right)$ principal stresses as 115 $\mathrm{MPa}, 100 \mathrm{MPa}$, and $85 \mathrm{MPa}$, respectively, where compression is taken as positive in each component. For simplicity, we did not introduce any depth dependence into these stresses. This uniform stress-field assumption cannot produce the depth-dependent variation of slip but can reproduce overall feature of the slip distribution (e.g., Aochi and Fukuyama, 2002). Because the predominant fault motion is strike-slip, we assumed that $\sigma_{2}$ is working in the vertical direction. The absolute value of $\sigma_{2}(100 \mathrm{MPa})$ assumed here corresponds to a lithostatic stress at a depth of $4 \mathrm{~km}$ for the average crustal density of $2500 \mathrm{~kg} / \mathrm{m}^{3}$. The absolute values of $\sigma_{1}(115 \mathrm{MPa})$ and $\sigma_{3}(85 \mathrm{MPa})$ are estimated to fit the stress drop roughly estimated in the previous section (Table 1). The $\sigma_{1}$ direction was varied between $\mathrm{N} 90^{\circ} \mathrm{E}$ and $\mathrm{N} 105^{\circ} \mathrm{E}$, which is based on the maximum principal strain directions measured by the triangular surveys (Geographical Survey Institute, 1994).

For the constitutive relation on the fault, we assume a simple slip-weakening friction law with a uniform slipweakening distance $\left(D_{c}\right)$ of $1 \mathrm{~m}$. In addition, we also need static $\left(\mu_{s}\right)$ and dynamic $\left(\mu_{d}\right)$ coefficients of friction to specify the yield $\left(\sigma_{y}\right)$ and frictional $\left(\sigma_{f}\right)$ stresses in the slip-weakening constitutive relation. $\sigma_{y}$ and $\sigma_{f}$ are computed by multiplying the normal stress with the friction coefficient $\left(\mu_{s}\right.$ for $\sigma_{y}$ and $\mu_{d}$ for $\left.\sigma_{f}\right)$. After several trial computations, we obtained optimum values of 0.1 and 0.01 for $\mu_{s}$ and $\mu_{d}$, respectively. Note that we did not take into account the effect of pore pressure, and hence, that $\mu_{s}$ here should be considered as an apparent coefficient of friction.

For a 2D representation of the stress field mapped on the fault, the stress drop $(\Delta \sigma)$ on each fault segment can be expressed as

$$
\Delta \sigma=\tau-\tau_{f}-\mu_{d} \sigma_{n}
$$

and

$$
\begin{aligned}
\tau & =\left(\sigma_{1}-\sigma_{3}\right) \sin (\theta-\varphi) \cos (\theta-\varphi) \\
\sigma_{n} & =\sigma_{1}-\left(\sigma_{1}-\sigma_{3}\right) \cos ^{2}(\theta-\varphi)
\end{aligned}
$$

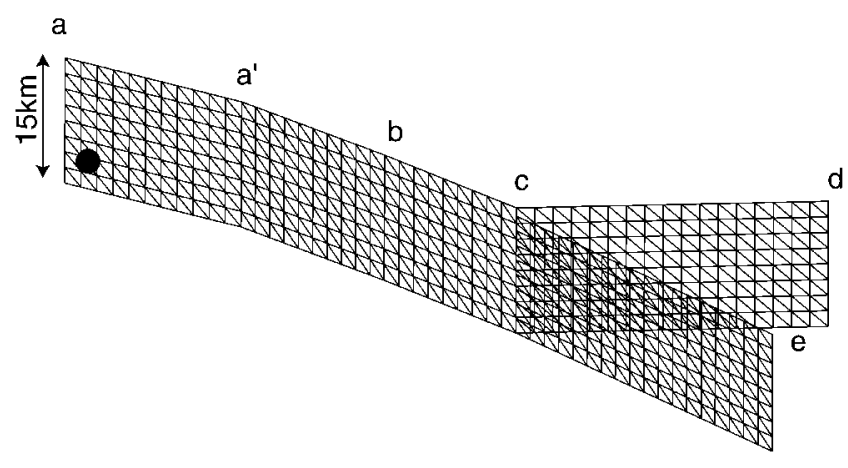

Figure 3. Fault model for the simulation of dynamic rupture propagation during the 1891 Nobi earthquake. Symbols a-e correspond to the locations shown in Figure 1. Along the fault segments aa'bcd the top margin of the fault is located on the ground surface, and along the buried segment ce, the top margin of the fault is assumed to be located at $1 \mathrm{~km}$ depth. The rupture-starting point is assumed to be located at a depth of $10 \mathrm{~km}$ near point a (see text for details).

where $\tau$ and $\sigma_{n}$ are the shear and normal stresses on the fault prior to the earthquake, respectively, $\tau_{f}$ is the shear stress after the earthquake, and $\varphi$ and $\theta$ are the fault strike and $\sigma_{1}$ directions, respectively. By fitting the stress drop in Table 1, we confirmed that the parameters we assumed here can reproduce stress drops nearly consistent with those given in Table 1 , when $\tau_{f}$ is negligibly small.

Numerical computations for dynamic rupture were done using the boundary integral equation method with triangular elements (Fukuyama et al., 2002; Fukuyama, 2003; Tada, 2006). This method enables us to simulate spontaneous dynamic rupture propagating on a fault under prescribed fault geometry, fault constitutive relation, and the stress field. The fault model consists of 1040 triangular elements with an average dimension of $1.8 \mathrm{~km}$ (Fig. 3). Free-surface effects are taken into account using a mirror image as made by Aochi and Fukuyama (2002). The rupture was initiated by assuming a high-stress concentration patch, which was broken immediately after the initiation of earthquake. The initiation patch is located close to the northern end of the fault system (point a) at a depth of $10 \mathrm{~km}$.

\section{Results of Dynamic Rupture Simulation}

Figure 4 shows the snapshots of dynamic rupture propagation during the Nobi earthquake. In the case when the $\sigma_{1}$ direction is $\mathrm{N} 105^{\circ} \mathrm{E}$ (Fig. 4c,d), which is more consistent with the maximum strain direction for the past 100 years after the earthquake (Fig. 2), the rupture could not propagate along the Umehara fault (cd) where the fault displacement had been actually traced after the earthquake (Matsuda, 1974). On the other hand, if $\sigma_{1}$ is oriented in the direction of $\mathrm{N} 90^{\circ} \mathrm{E}$ (Fig. $4 \mathrm{a}, \mathrm{b}$ ), the rupture was also able to propagate along the Umehara fault. In this case, the computed surface slip is roughly consistent with the observed one. 
The condition that the rupture could propagate or not toward the Umehara fault, when the rupture reached at the southern end (point $c$ ) of the Neodani fault, appears to depend on the initial shear-stress level accumulated on the Umehara fault. For the $\sigma_{1}$ direction of $\mathrm{N} 105^{\circ} \mathrm{E}$, the shear stress was not accumulated on the Umehara fault as seen at the initial stage $(t=0)$ (Fig. 4c,d). For the $\sigma_{1}$ direction of $\mathrm{N} 90^{\circ} \mathrm{E}$, on the other hand, the initial shear-stress level on the Umehara fault is almost the same as that on the Nukumi and Neodani faults. This may why the rupture could propagate both along the Neodani and Umehara faults. Because the maximum principal tectonic stress is oblique to the GifuIchinomiya line, the initial shear stress became insensitive to a slight change of the principal stress direction, which could make the rupture propagate along the Gifu-Ichinomiya line in both cases.

In this simulation, rupture velocity is controlled by the balance between the release of strain energy and consumption of fracture energy (Fukuyama and Olsen, 2002). Fracture energy is controlled by $\mu_{s}$ and $\mu_{d}$ as well as $D_{c}$. Because these parameters are simplified and assumed to be uniformly distributed over the fault here, we could not tune the rupture velocity well. A stable solution was that the rupture propagates with super-shear velocity along the main fault segments before the branch. As Kame and Yamashita (1999), Poliakov et al. (2002), and Kame et al. (2003) suggested, for the rupture to propagate along both of the branches, the rupture should propagate fast enough, which is consistent with the present simulation, while Mikumo and Ando (1976) estimated a rather slow rupture velocity by kinematic forward modeling of the observed waveforms.

Figure 5 shows the snapshots of dynamic rupture propagation, assuming that there is a $1-\mathrm{km}$ gap between the southern edge of the Neodani fault and the northern edge of the Gifu-Ichinomiya line. It is found that the general features of the rupture propagating on the Nukumi, Neodani, and Umehara faults do not change. This is because the branch angle between the Umehara fault (cd) and Gifu-Ichinomiya line (ce) is greater than $30^{\circ}$, and under this situation the rupture propagating along each branched fault does not interfere with the other, as has been shown by Aochi et al. (2000).

Note that the rupture did propagate along the Umehara fault and not along the Gifu-Ichinomiya line for the case of the $\sigma_{1}$ direction is $\mathrm{N} 90^{\circ} \mathrm{E}$ although it propagated along the Gifu-Ichinomiya line for $\mathrm{N} 105^{\circ} \mathrm{E}$ case. Thus, the existence of the gap between the Neodani fault and Gifu-Ichinomiya line prevented the rupture from propagating further along the Gifu-Ichinomiya line for the $\mathrm{N} 90^{\circ} \mathrm{E}$ case, but the rupture could overcome this barrier for the $\mathrm{N} 105^{\circ} \mathrm{E}$ case. This implies that for the rupture to propagate both on the Umehara fault and the Gifu-Ichinomiya line, it is important whether the Gifu-Ichinomiya line exists as a weak line and whether its northern edge is connected to the southern edge of the Neodani fault. According to Kaneda (2005, personal comm.) there is a short right-lateral fault on the surface (called the
Kochibora fault; see Fig. 1) between the Neodani fault and the Gifu-Ichinomiya line, which is conjugated to the Neodani fault. If this Kochibora fault slipped at depth during the Nobi earthquake, the Gifu-Ichinomiya line could rupture during the earthquake because it connected the Neodani fault and the Gifu-Ichinomiya line at depth, which would make the rupture propagate more easily along the Gifu-Ichinomiya line. These results also suggest that the Gifu-Ichinomiya line would not break when any weak tectonic lines had not existed there or if a barrier exists between the Neodani fault and Gifu-Ichinomiya line that is strong enough to resist dynamic rupture during the earthquake.

\section{Discussions}

Now we compare the obtained features of rupture propagation with the ground motions observed during the earthquake. Although there were no instrumental measurements of strong ground motions at that time, Omori (1900) investigated zones severely damaged because of the earthquake (Fig. 6). These zones appear to correspond to the ruptured fault traces during the earthquake, covering the Umehara fault and the Gifu-Ichinomiya line (see Fig. 6). One should be careful, however, when comparing the modeling results with the damage distribution because the distribution could include the effect of local site amplification. Actually, the Nobi plain is covered by a sedimentary basin located south of the source region of the Nobi earthquake. On the other hand, however, we should also take into account the observations that buried faults generate stronger ground shaking than surface-breaking faults (Somerville, 2003; Kagawa et al., 2004). For this reason, we think that the distribution of damaged zone could be enlarged by the local site effects but its basic feature was caused by the faulting itself during the earthquake. This could also be the reason why the GifuIchinomiya line did not appear on the surface during the Nobi earthquake. Because the shallow sediments did not sustain any stress, stress drop could not occur there during the rupture, which might prevent the rupture from reaching the surface.

In this fault modeling we assumed a pure-strike-slip vertical fault. Note, however, that significant vertical offsets were observed on the ground surface. Because there is no information on the dip of the deeper part of the faults, we did not take into account the dip-slip components. The initial shear stress and the slip direction on the fault depend strongly on the dip of the fault. Actually, the stress field near the surface and at seismogenic depths could be very different, and the slip direction could also change because of the difference of the absolute magnitude of stress (Spudich, 1992; Guatteri and Spudich, 1998). Even if the fault plane of the Gifu-Ichinomiya line dips some amount as suggested by Nakano et al. (2003), the computation result will not change significantly because the amount of shear stress on the fault before the earthquake might not be quite different from that for the strike-slip case. 


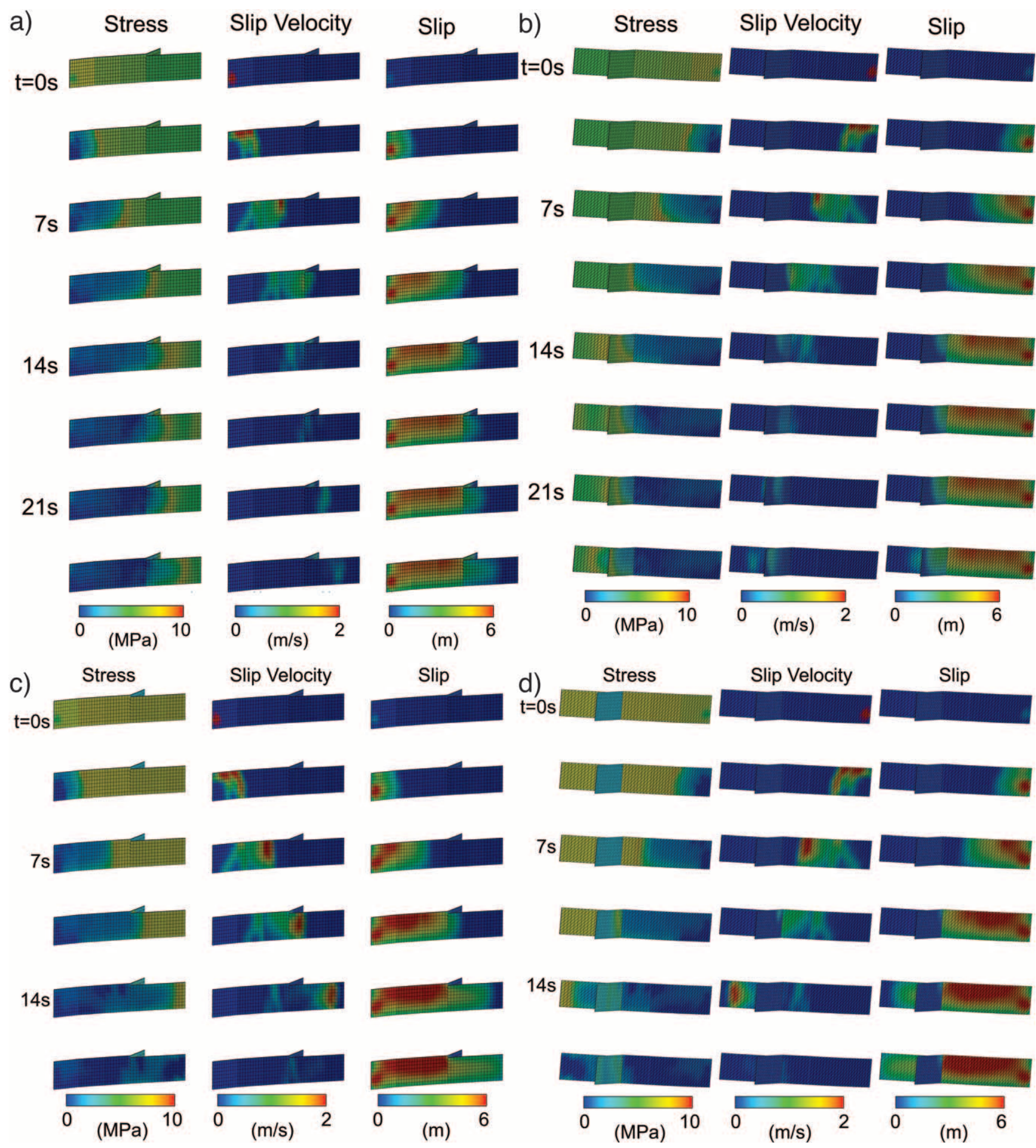

Figure 4. Results from numerical simulations for dynamic rupture propagation with a buried fault segment (ce). Snapshots of shear stress, slip velocity and slip on the fault segments are shown at an interval of every $3.5 \mathrm{sec}$. (a) and (b) present the case of $\sigma_{1}=\mathrm{N} 90^{\circ} \mathrm{E}$, and (c) and (d) present the case of $\sigma_{1}=\mathrm{N} 105^{\circ} \mathrm{E}$. Cases (a) and (b) and cases (c) and (d) show the same results, respectively, as viewed from different directions, to see the whole rupture patterns. Scales are shown at the bottom of each sequence of snapshots. Note that the rupture propagates on the two branched faults in the cases (a) and (b) whereas it does not do that in cases (c) and (d). 


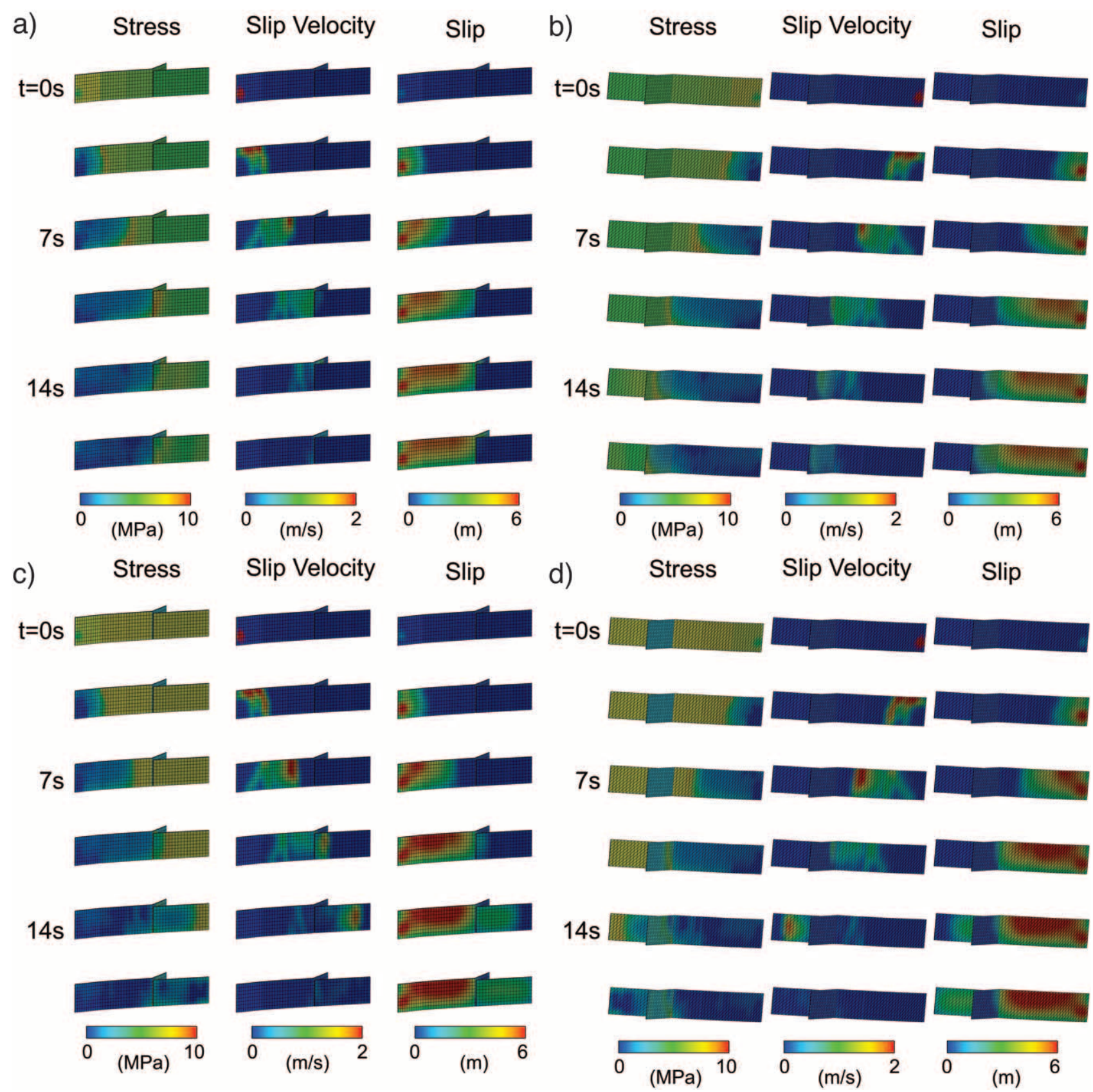

Figure 5. Results from numerical simulations with a $1.0 \mathrm{~km}$ gap between the northern edge of the buried fault segment (ce) and the southern edge of the surface-ruptured fault (bc). Snapshots of shear stress, slip velocity, and slip on the fault are shown at an interval of every $3.5 \mathrm{sec}$. (a) and (b) are for the case of $\sigma_{1}=\mathrm{N} 90^{\circ} \mathrm{E}$, and (c) and (d) are for the case of $\sigma_{1}=\mathrm{N} 105^{\circ} \mathrm{E}$. Cases (a) and (b) and cases (c) and (d) show the same results, respectively, as viewed from different directions, to see the whole rupture patterns. Scales are shown at the bottom of each sequence of snapshots. Note that the rupture propagates only on the Umehara fault (cd) but not on the Gifu-Ichinomiya line (ce) in the case of $\sigma_{1}=\mathrm{N} 90^{\circ} \mathrm{E}$ (a) and (b), whereas it does not propagate on the Umehara fault (cd) but propagated on the Gifu-Ichinomiya line (ce) in the case of $\sigma_{1}=\mathrm{N} 105^{\circ} \mathrm{E}(\mathrm{c})$ and (d). 


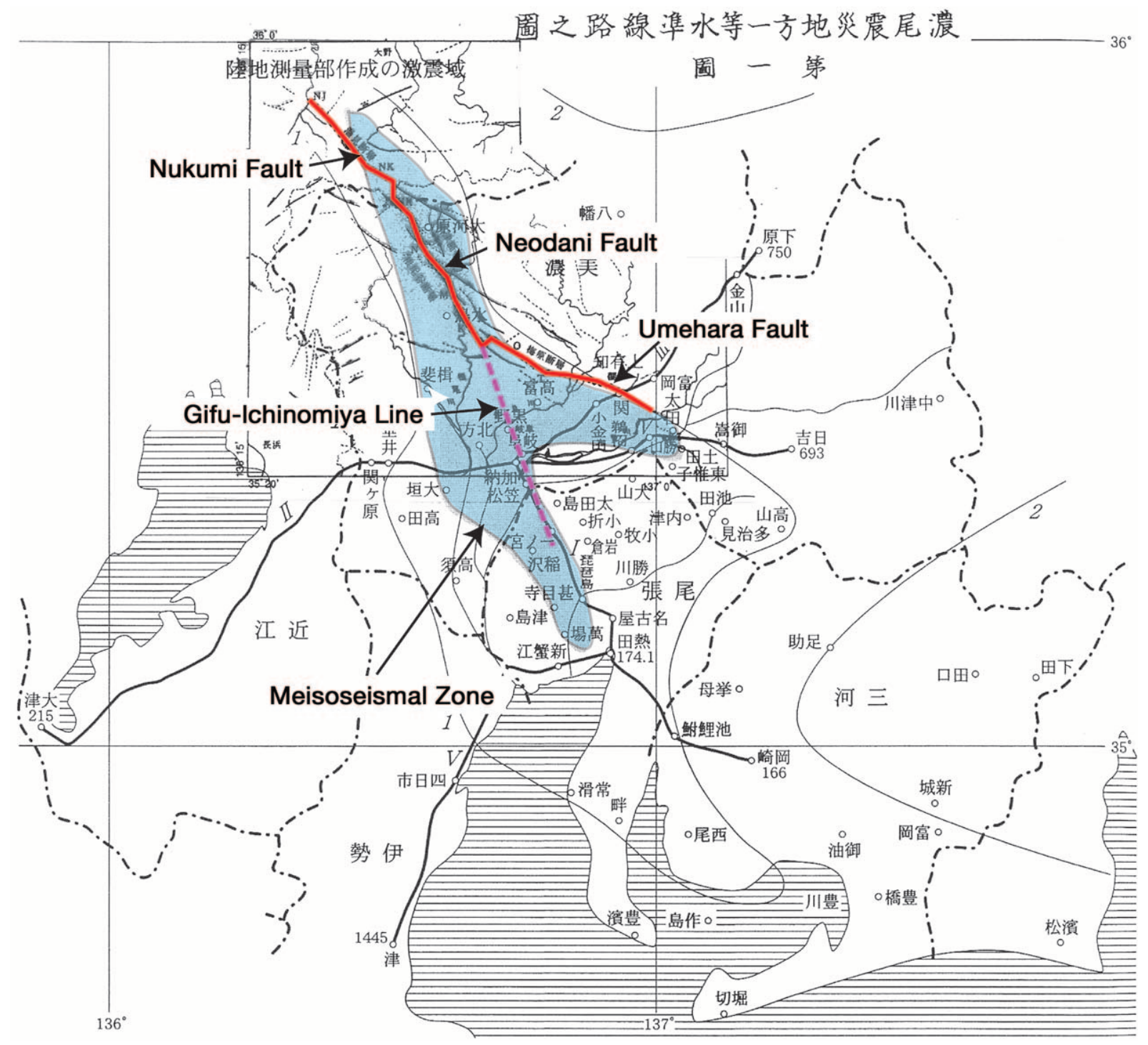

Figure 6. Distribution of meisoseismal zone (light blue; Muramatsu et al., 2002) is plotted on the active-fault traces of the Nobi earthquake (red line; Matsuda, 1974) with the buried fault trace of the Gifu-Ichinomiya line (purple dotted line; Mikumo and Ando, 1976).

There might be a possibility that the tectonic stress direction rotates along the fault trace, which might affect the dynamic rupture propagation as Aochi and Fukuyama (2003) estimated for the 1992 Landers earthquake. But by looking at the strain change in the source region (Fig. 2), the maximum principal direction did not change, suggesting a rather uniform stress field in this region. Note that this strain distribution is after the earthquake and we have no information about before the earthquake. For the Landers case, a tectonic boundary exists at the center of the fault, but for the present case, no tectonic boundaries are reported in the source region.

\section{Conclusions}

We have attempted to reproduce a dynamic rupture process of the 1891 Nobi earthquake, using its fault geometry estimated from the observed surface-fault slips and the stress field inferred from geodetic observations. For this purpose, numerical computations have been made by using the boundary integral equation method. The results obtained from these numerical simulations suggest that a buried fault called the Gifu-Ichinomiya line should exist as a southern extension of the Neodani fault and may have been broken during the Nobi earthquake. In addition, for dynamic rupture propagating on the two branched faults, including the Umehara fault which is a southeastern segment, the principal 
stress direction should be oriented in $\mathrm{N} 90^{\circ} \mathrm{E}$, which is slightly rotated counterclockwise from the average direction inferred from geodetic observations.

\section{Acknowledgments}

We thank Atsumasa Okada and Ikuei Muramatu for their constructive comments on the present study. Reviews by Fred F. Pollitz and two anonymous reviewers were helpful. This work was supported by the National Research Institute for Earth Science and Disaster Prevention project "Research on Mechanics of Earthquake Occurrence" and Grant-in-Aid SE(C) 15607020 by the Ministry of Education, Culture, Sports, Science, and Technology, Japan.

\section{References}

Aichi Prefecture (1998). Research Report on the Gifu-Ichinomiya and Yoro-Kuwana-Yokkaichi fault zones, 118 pp. (in Japanese).

Aichi Prefecture (2000). Underground structure in the Nobi plain, in Proc. of the 1st Workshop on Sedimentary Basin Underground Structure, pp. 61-70 (in Japanese).

Andrews, D. J. (1989). Mechanics of fault junctions, J. Geophys. Res. 94, 9389-9397.

Aochi, H., E. Fukuyama, and M. Matsu'ura (2000). Selectivity of spontaneous rupture propagation on a branched fault, Gephys. Res. Lett. 27, 3635-3638.

Aochi, H., and E. Fukuyama (2002). Three-dimensional nonplanar simulation of the 1992 Landers earthquake, J. Geophys. Res. 107, no. B2, doi 10.1029/2000JB000061, ESE4-1-4-12.

Aoki, H., T. Tada, Y. Sasaki, T. Ooida, I. Muramatu, H. Shimamura, and I. Furuya (1972). Crustal structure in the profile across central Japan as derived from explosion seismic observations, J. Phys. Earth 20, 197-223.

Archuleta, R. (1984). A faulting model for the 1979 Imperial Valley earthquake, J. Geophys. Res. 89, 4559-4585.

Bouchon, M., and D. Streiff (1997). Propagation of a shear crack on a nonplanar fault: a method of calculation, Bull. Seism. Soc. Am. 87, $61-66$.

Chinnery, M. A. (1969). Theoretical fault models, Publications of the Dominion Observatory, Ottawa, 37, 211-223.

Cruz-Atienza, V. M., and J. Virieux (2004). Dynamic rupture simulation of non-planar faults with a finite-difference approach, Geophys. J. Int. 158, 939-954.

Deng, Q., S. Chen, F. Song, S. Zhu, Y. Wang, W. Zhang, D. Jiao, B. C. Burchfiel, P. Molnar, L. Royden, and P. Zhang (1986). Variations in the geometry and amount of slip on the Haiyuan (Nanxihaushan) fault zone, China and the surface rupture of the 1920 Haiyuan earthquake, in Earthquake Mechanics, S. Das, J. Boatwright, and C. H. Scholz (Editors), American Geophysical Monograph 37, 169-182.

Fukuyama, E. (2003). Non-planar fault geometry and stress field around the fault (AGU fall meeting abstract), EOS Trans. AGU, S51B-04.

Fukuyama, E., and K. B. Olsen (2002). A condition for super-shear rupture propagation in a heterogeneous stress field, PAGEOPH 159, 20472056.

Fukuyama, E., T. Tada, and B. Shibazaki (2002). Three dimensional dynamic rupture propagation on a curved/branched fault based on boundary integral equation method with triangular elements, (AGU fall meeting abstract), EOS Trans. AGU NG62A-0930.

Geographical Survey Institute (1973). Vertical movements in Chubu district (1), Rep. Coord. Comm. Earthquake Pred., 9, 74-78 (in Japanese).

Geographical Survey Institute (1994). Summary of observations for earthquake prediction in Japan (Part 2): Kanto and Chubu areas, Special Report of the Regional Sub-Committees, Rep. Coord. Comm. Earthquake Pred., 52 87-132 (in Japanese).

Geographical Survey Institute (1999). Velocities of horizontal crustal de- formation in Japan, derived from continuous GPS observations, Rep. Coord. Comm. Earthquake Pred. 61, 555-572 (in Japanese).

Guatteri, M., and P. Spudich (1998). Coseismic temporal changes of slip direction: the effect of absolute stress on dynamic rupture, Bull. Seism. Soc. Am. 88, 777-789.

Haeussler, P. J., D. P. Schwartz, T. E. Dawson, H. D. Stenner, J. J. Lienkaemper, B. Sherrod, F. R. Cinti, P. Montone, P. A. Craw, A. J. Crone, and S. F. Personius (2004). Surface rupture and slip distribution of the Denali and Totschunda faults in the 3 November 2002 M 7.9 earthquake, Alaska, Bull. Seism. Soc. Am. 94, S23-S52.

Harris, R. A., and S. M. Day (1993). Dynamics of fault interaction: parallel strike-slip faults, J. Geophys. Res. 98, 4461-4472.

Harris, R. A., and S. M. Day (1999). Dynamic 3D simulations of earthquakes on en echelon faults, Geophys. Res. Lett. 26, 2089-2092.

Harris, R. A., R. J. Archuleta, and S. M. Day (1991). Fault steps and the dynamic rupture process: 2-D numerical simulations of a spontaneously propagating shear fracture, Geophys. Res. Lett. 18, 893-896.

Harris, R. A., J. F. Dolan, R. Hartleb, and S. M. Day (2002). The 1999 Izumit, Turkey, earthquake: a 3D dynamic stress transfer model of intraearthquake triggering, Bull. Seism. Soc. Am. 93, 1154-1170.

Iida, K., and H. Aoki (1959). Gravity anomalies and subterranean mass distribution, with special reference to the Nobi plain, J. Geod. Soc. Jpn. 5, 88-91 (in Japanese).

Ikeda, R., K. Omura, Y. Iio, and H. Tsukahara (1996). Scientific drilling and in-situ stresses in active fault zones at Neodani, central Japan, in Proc. 8th International Symposium on the Observation of the Continental Crust Through Drilling, Tsukuba, Japan, 30-35.

Kagawa, T., K. Irikura, and P. G. Somerville (2004). Differences in ground motion and fault rupture process between the surface and buried rupture earthquakes, Earth Planets Space 56, 3-14.

Kame, N., and T. Yamashita (1999). Simulation of the spontaneous growth of a dynamic crack without constraints on the crack tip path, Geophys. J. Int. 139, 345-358.

Kame, N., J. R. Rice, and R. Dmowska (2003). J. Geophys. Res. 108, no. B5, 2265, doi 10.1029/2002JB002189, ESE13-1-13-20.

Kase, Y., and K. Kuge (1998). Numerical simulation of spontaneous rupture processes on two coplanar faults: the effect of geometry on fault interaction, Geophys. J. Int. 135, 911-922.

Kase, Y., and K. Kuge (2001). Rupture propagation beyond fault discontinuities: Significance of fault strike and location, Geophys. J. Int. 147, 130-342.

Koto, B. (1893). On the cause of the great earthquake in central Japan, $J$. Coll. Sci., Imp. Univ. Tokyo 5, 295-353.

Matsuda, T. (1974). Surface faults associated with Nobi (Mino-Owari) earthquake of 1891, Japan, Spec. Rep. Earthquake Res. Inst. 13, 85126 (in Japanese).

Mikumo, T., and M. Ando (1976). A search into the faulting mechanism of the 1891 great Nobi earthquake, J. Phys. Earth 24, 63-87.

Mikumo, T., K. Hirahara, and T. Miyatake (1987). Dynamical fault rupture processes in heterogeneous media, Tectonophysics 144, 19-36.

Muramatu, I. (1963). Distribution of seismic intensity and crustal deformation in the region destroyed by the great Nobi earthquake of October 28, 1891, Res. Rep. (Natural Sci.), Gifu Univ. 3, 202-224 (in Japanese).

Muramatsu, I., T. Matsuda, and A. Okada (2002) The 1891 Nobi Earthquake and Neodani Fault Zone, Kokon Shoin, Publishers, Tokyo, 354 pp. (in Japanese).

Nakano, M., K. Yamaoka, and J. Miyakoshi (2003). A fault model of GifuIchinomiya line on the 1891 Nobi earthquake, in Prog. Abstr., 2003 Fall Meeting, Seism. Soc., Japan, B053.

Nakata, T., H. Tsutsumi, R. S. Punongbayan, R. E. Rimando, J. Daligdig, and A. Daag (1990). Surface faulting associated with the Philippne earthquake of 1990, J. Geography 99, 515-532 (in Japanese).

Oglesby, D. D., S. M. Day, Y-G. Li, and J. E. Vidale (2003). The 1999 Hector Mine earthquake: the dynamics, Bull. Seism. Soc. Am. 93, 2459-2476.

Oglesby, D. D., D. S. Dreger, R. A. Harris, N. Ratchkovski, and R. Hansen 
(2004). Inverse kinematic and forward dynamic models of the 2002 Denali fault earthquake, Alaska, Bull. Seism. Soc. Am. 94, S214S233.

Okada, A. (2002). Geological properties of the Nobi active fault system, in The 1891 Nobi Earthquake and Neo-dani Fault Zone, I. Muramatu, T. Matsuda, and A. Okada (Editors), Kokon-Shoin, Tokyo, 341 pp. (in Japanese).

Omori, F. (1894). General report on the Nobi earthquake, Report of Gifu Observatory, 48-88 (in Japanese).

Omori, F. (1900). Note on the great Mino-Owari earthquake of Oct. 28th, 1891, Publication of the Earthquake Investigation Committee in Foreign Language 4, 13-24.

Omori, F. (1910). On classification of earthquakes, Report of the Earthquake Investigation Committee A68, 3-19 (in Japanese).

Ooida, T., I. Yamada, T. Tada, K. Ito, K. Sugiyama, and Y. Sasaki (1971). Microearthquake activity in central Honshu, Japan, Part I. Seismicity of microearthquakes in the vicinity of the Neo Valley fault, Zisin 24, 240-247 (in Japanese).

Poliakov, A. N. B., R. Dmowska, and J. R. Rice (2002). Dynamic shear rupture interactions with fault bends and off-axis secondary faulting, J. Geophys. Res. 107, no., 2295, doi 10.1029/2001JB000572, ESE61-6-18.

Politz, F. F., and I. S. Sacks (1994). Fault model of the 1891 Nobi earthquake from historic triangulation and leveling, J. Phys. Earth 42, $1-43$.

Sato, H. (1974). A study of horizontal movement of the earth crust associated with destructive earthquakes in Japan, Bull. Geogr. Surv. Inst. 19, 89-130.

Sibson, R. H. (1986). Rupture interaction with fault jogs, in Earthquake Mechanics, S. Das, J. Boatwright, and C. H. Scholz (Editors), American Geophysical Monograph 37, 157-167.
Somerville, P. G. (2003). Magnitude scaling of the near fault rupture directivity pulse, Phys. Earth Planet. Interiors 137, 201-212.

Spudich, P. K. P. (1992). On the inference of absolute stress levels from seismic radiation, Tectonophysics 211, 99-106.

Sugisaki, R., and K. Shibata (1961). Geochemical study on ground water: surface geology and aquifers in the Nobi plain, J. Geol. 67, 335-345 (in Japanese).

Sugisaki, R., and K. Shibata (2003). Reappraisal of the Gifu-Ichinomiya fault: points at issue for recognition of concealed fault under alluvial plain, Zisin 56, 281-296 (in Japanese).

Tada, T. (2006). Stress Green's functions for a constant slip rate on a triangular fault, Geophys. J. Int. 164, 635-669.

Tada, T., and T. Yamashita (1997). Non-hypersingular boundary integral equations for two-dimensional non-planar crack analysis, Geophys. $J$. Int. 130, 269-282.

Yokoo, Y., and T. Horiuchi (1969). Map of Ground Structure in Nagoya, Corona Publishing Co. Ltd., Tokyo (in Japanese).

Yoshida, Y., and K. Abe (1992). Source mechanism of the Luzon, Philippines earthquake of July 16, 1990, Geophys. Res. Lett. 19, 545-548.

National Research Institute for Earth Sciences and Disaster Prevention Tsukuba, 305-0006, Japan

(E.F.)

Instituto de Geofisica

Universidad Nacional Autonoma de Mexico

Ciudad Universitaria, Mexico

04510 D.F., Mexico

(T.M.)

Manuscript received 27 July 2005. 